\title{
Corrigendum to: Linkage and candidate gene studies of autism spectrum disorders in European populations
}

Richard Holt, Gabrielle Barnby, Elena Maestrini, Elena Bacchelli, Denise Brocklebank, Inês Sousa, Erik J Mulder, Katri Kantojärvi, Irma Järvelä, Sabine M Klauck, Fritz Poustka, Anthony J Bailey and Anthony P Monaco, the EU Autism MOLGEN Consortium

European Journal of Human Genetics (2010) 18, 1020; doi:10.1038/ejhg.2010.99

Correction to: European Journal of Human Genetics (2010) 18, 1013-1019; doi:10.1038/ejhg.2010.69; published online 5 May 2010

Since the publication of the above paper, the authors noticed that one name is missing from the list of Autism MOLGEN members in the Appendix:

\section{Jeremy Parr}

Department of Psychiatry, University of Oxford, Oxford, UK

The authors would like to apologise for this mistake. 